\title{
LA "AFRENTA DE CORPES", NOVELA PSICOLÓGICA
}

Pese a los cazadores profesionales de tópicos y motivos tradicionales, a los preceptistas y a quienes niegan personalidad estilística a los poetas que no han tenido la fortuna de nacer antes de 1800 , hoy ya no es necesario justificar el estudio de una epopeya primitiva $y$ medieval en cuanto fruto de la inspiración individual y como ejemplo de expresión personal. Es evidente que las restricciones impuestas por la tradición, las reglas y el despotismo espiritual no han podido impedir la aparición de una poesía auténtica e inmediata. $\mathrm{Y}$ hasta me atrevería a afirmar que el arte, en cuanto tal, nunca lo ha sido más genuinamente que cuando ha brotado de un sentimiento religioso, aunque este sentimiento sea extra-artístico por definición.

Los episodios poco menos que inventados que llenan la segunda mitad del poema histórico del Cid _-las "Bodas", la "Afrenta de Corpes" y las "Cortes" - han sido analizados, como todo el Poema, por varios críticos modernos (y entre ellos, algunos de los más autorizados) desde el punto de vista estético, o sea como obra de arte. En mi opinión, el que ha logrado acercarse con más tino al secreto de la "unidad poética" de esos episodios es el chileno Eleazar Huerta, por más que su libro no parezca gozar de aprecio en la bibliografía más recientel. Huerta, percatándose de la asombrosa capacidad introspectiva del juglar, utiliza conceptos de la psicología moderna para hacer resaltar las intenciones del poeta medieval: " . . los infantes proyectan su ruindad sobre los mejores, a quienes envidian"; "la envidia y el odio de raíz individual se enmascaran bajo la socorrida fórmula de orgullo de casta", etc. ${ }^{2}$ Además, Huerta ve al Cid -aunque no siempre - en su humanidad y no en su sobrehumanidad, según el ejemplo del maestro Menéndez $\mathrm{Pidal}^{3}$. Por mi parte, y a

1 Eleazar Huerta, Poética del "Mio Cid", Santiago de Chile, 1948; cf. E. DE Chasca, Estructura y forma en el "Poema de mio Cid", Iowa City, 1955, pp. $135^{-1} 3^{6}$.

${ }^{2}$ Op. cit., pp. 188-189; insiste igualmente en que la cobardía de los Infantes no es sino accesorio de su lacra moral básica, el egoísmo (pp. 177-178, 209).

3 Dice don Ramón Menéndez Pidal, El Cid Campeador, Buenos Aires, 1950, pp. 312-313, refiriéndose al Cid de la historia: "Muy lejos de creer que toda la vida ambiente no tiene otro fin sino preparar el advenimiento del superhom. bre, siente que nada es la más fuerte individualidad del hombre sin el pueblo 
pesar de mi aversión al empleo de conceptos modernos como medio de comprensión de lo antiguo, me veré obligado a recurrir al "complejo de inferioridad" para tratar de explicar la subestructura secreta de la "novela psicológica" intitulada "Afrenta de Corpes".

Pero, se me objetará: ¿por qué hacer una interpretación psicológica, siendo tantos los peligros que se corren - a pesar de las precauciones que puedan tomarse- al aplicar ese método a un texto primitivo? Sin tales intrusiones, el pasaje que nos ocupa no es sino un cuento en el cual no hay nada que comentar, una vez que lo aceptamos como episodio ingenuamente sensacional, escrito por un poeta de aspiraciones poco refinadas (como conviene a su época y a su situación). Y también se me objetará que los episodios inventados —las "Bodas" y la "Afrenta"- no pueden parangonarse con las partes del Poema basadas en la realidad histórica próxima.

Pero la razón interior por la cual acogemos una introspección que nos permita penetrar a través de la corteza de lo que, leído irreflexivamente, parece tan sólo un cuento algo pueril, es la dignidad misma del poeta —aunque sea "primitivo"-, dignidad que ya se para el cual vive”. Y Huerta, hablando del Cid del Poema: “. . . sigue siendo de carne y hueso, ... no puede convertirse en la estatua de sí mismo" (p. 176). Verdad es que Huerta, pese a intuición tan sana, usa y abusa de la "dimensión mítica" del Cid en las pp. 170 ("rango mítico, sobrehumano"), 187, 196 et passim, punto de vista que, por su exclusividad, resta méritos a la interpretación de don Américo Castro, "Poesía y realidad en el Poema del Cid", artículo de 1935 reimpreso en sus Semblanzas y estudios españoles, Princeton, 1956, pp. 3 ss. Yo, por mi parte, oponiéndome a DE CHAsca, para quien el Cid del Poema tiene carácter suprapersonal de "héroe nacional" (op. cit., pp. 122 ss.), me sumo a quienes opinan que el Cid alcanza su fama y dimensión de héroe precisamente gracias al retrato personalísimo que de él se hace en el Poema. Dice también Menéndez Pidal que "por fuerza hemos de volver siempre los ojos [al Poema] cuando deseamos conocer algo de la vida íntima del Cid" (op. cit., p. 275). El talento del juglar estribaba en la introspección psiquica, en la evocación, tan sucinta y escueta como conmovedora, de situaciones humanas, y no en la perspectiva pública e histórica. No tiene idea clara, por ejemplo, de la verdadera importancia de Yusuf y su movimiento almorávide. Para él, este Yusuf (series 88 ss.) no es sino uno de tantos, un comparsa más que contribuye a hacer resaltar la persona del héroe central a quien -eso sí- todo lo que es público (batallas, etc.), le sale inevitablemente bien en el Poema, según el estilo de tantas epopeyas y de tantas novelas populares, de tiempos pasados y presentes. "No habla de cruzada, pero la siente", dice acertadamente Hucrta, p. 187; y se puede afirmar que, de tal modo, cobra un poco de dignidad hasta el obispo don Jerome, ejemplar repulsivo del tipo anfibio del clérigo batallador, con su "sabor que avía de algún moro matare" (vs. 2368 ss.). ¿Y cómo podría pedirse de un juglar dei siglo xil -aunque poeta genial- la perspectiva histórica de un cstudioso moderno, si ni aun el cronista contemporáneo de cultura latina sabe mucho más que los nombres, y ni siquiera se da cuenta cabal de la importancia pública de lo que habla, cuando dice: "Interim vero audiuit quod Juzef rex hysmaelitarum et alii... uenerant obsidere castrum... quem christiani tune possidebant" (Historia Roderici, cap. 32, apud MENÉndez PIDAL, La España del Cid, $4^{3}$ ed., Madrid, 1947, p. 933)? 
nos ha impuesto en la primera parte del Cantar, y que quisiéramos encontrar también en la segunda. Las extraordinarias dotes de psicólogo que revela el juglar ya han sido señaladas por estudiosos como Menéndez Pidal, Castro, De Chasca y Spitzer, los cuales han visto cómo la ira del rey se va cambiando en amor y respeto por el Cid, y cómo el héroe mismo se va desarrollando, desde la desventurada situación de desterrado hasta el papel ilustre de "casi-rey" de Valencia. En cuanto a la tercera gran sección -las "Cortes"- no tenemos nada que añadir o que echar de menos; y sin embargo, también las Cortes están "inventadas", ya que no son sino la consecuencia directa del cuento inventado de las "Bodas" y la "Afrenta" Es el Cid -.y no los Infantes- quien vuelve a ocupar en las Cortes el centro de la acción, dirigiéndola por medio de su "santidad maliciosa". Con una mezcla única de razón calculadora y de elemental pasión, sabe refrenar la furia y "rencor" hasta el momento en que su desahogo pueda servir a la causa que defiende (vs. 3253 ss.). Me refiero a las tres "demandas" y a su graduación, magistralmente premeditada, desde lo material y comercial hasta lo patético y caballeresco.

Pues bien: cabe suponer que un poeta que ha leído tan profunda y sutilmente en el alma de su héroe principal, lo haya hecho también en la de los dos antihéroes que le opone, aunque el resul-

${ }^{4}$ Sobre lo poco que podría considerarse como real en todo cuanto a los Infantes se refiere, véase Menéndez Pidal, El Cid Campeador, pp. 276-277, y su gran edición del Poema, t. 2, s. v. "Carrión" (véase infra, nota 13). Sin embargo, en su artículo "Filología e historia", $Z R P h, 64$ (1944), 228-229, insiste en la posibilidad de que las "Bodas" tengan base en la realidad histórica. LEo SPITzER, "Sobre el carácter histórico del Cantar de mio Cid", NRFH, 2 (1948), 105-117, hace resaltar el aspecto novelístico de la "Afrenta", parte orgánica de un poema que es, según él, "biografía epopeyizada".--Mi amigo Joe Gulsoy, de la Universidad de Chicago, me ha comunicado (en carta del 4 de diciembre de 1958) su idea del Poema, en la cual va implícita una justificación de sus partes inventadas y no históricas. Para mostrar su aceptable visión de la "unidad estructural" del Poema de mio Cid, copio unas frases de esa carta: "Me parece que será muy pertinente una explicación de por qué incluyó el poeta este episodio [del crimen de Corpes]; así podremos explicarnos también esa abrupta conclusión de las bodas con reyes... Todo el Poema se basa en el conflicto entre el Cid, un «infanzón», y los nobles, «ricos homes»; su destierro, la pérdida del amor del rey y de su honor, fueron causados por los nobles... El Cid triunfa... recobrando su honra, y muchos críticos dicen que el Poema debió terminar ahí. Pero el poeta prosigue su relato para hacer que el Cid triunfe sobre sus adversarios los nobles; por eso añade el episodio de los Infantes de Carrión, y así los ridiculiza ante los escuderos del Cid y hace de ellos unos odiosos criminales. Al final, cuando se reúnen las Cortes, el crimen de los Infantes... se convierte en preocupación de los familiares de éstos, es decir, de los nobles, los antiguos enemigos del Cid... Toda la segunda parte del Poema se funda en la trama de venganza del Cid, y el poeta no podía tener mejor ocasión para dar remate dramático a su propósito. Creo que así se entiende mejor por qué las embajadas entran de golpe en la corte. La venganza se realiza así... no sólo sobre los Infantes, sino sobre los nobles en general, enemigos del héroe épico". 
tado de su introspección psíquica no haya quedado tan claro, a través de la presentación poética, en el caso de los Infantes como en el del Gid. Tal diferencia - diferencia en cuanto a la expresión, no en cuanto a la intuición - estriba en la mayor dificultad y el menor entusiasmo con que se develan los secretos de dos personajes criminales y mezquinos, frente a la simpatía con que, naturalmente, se habla de un alma heroica. Al lector, por lo tanto, le corresponde suplir, con su propia intuición secundariamente creadora, la motivación psíquica que en el caso de los Infantes ha dejado el poeta en el sustrato de su cuento, sugiriéndola más que presentándola. Y añadamos ya que, para comprender este aparente descuido o despreocupación del juglar, no nos bastará estudiar el comportamiento de los Infantes en la "Afrenta", sino también en el episodio de las "Cortes", por más que en éste vuelvan a ocupar un segundo plano 5 .

Comencemos por hacer un esbozo del episodio de la "Afrenta", tal como se le muestra a un lector ingenuo y no reflexivo, no preocupado por la "unidad poética" de lo que lee. Para él, los hechos se resumen como sigue: Dos jóvenes condes que no aprecian sino la propia nobleza y que, por lo tanto, deberían cuidar sobre todo de su buena fama, como gente de "natura tan alta" (v. 3275), no sólo han revelado su cobardía ante un círculo de caballeros y soldados que nada estiman fuera de la valentía; no sólo se han comprometido, cegados por la riqueza y el poder de un hombre de más bajo nacimiento, a casarse con sus hijas, sino que además, heridos en su susceptibilidad cobarde, propia de personas que prefieren echar en espaldas ajenas las consecuencias de sus defectos, deciden huir con sus mujeres engañando la magnanimidad ingenua, la "ceguera voluntaria" del padre; $y$, habiendo huido, ponen en práctica un plan premeditado en que no parece haber la menor huella de sentido común, la prudencia más elemental, cosa rara en individuos que sólo habían obedecido a la más fría y calculadora prudencia al contraer matrimonio con unas mujeres a quienes ahora, tan irracionalmente, van a repudiar. En una palabra, los Infantes actúan en el robledo de Corpes como unos insensatos que, al entregarse a una furia desmesurada, olvidan sus ideales de "honra y fama", fomentados con tanto cuidado antes y - como veremos- también después. En un momento destruyen lo que durante largos meses habían edificado: un futuro de vida rica y segura. Es obvio que los dineros

* Aún más se debe decir respecto de la estrecha relación de todo el episodio inventado de los Infantes - desde las "Bodas" hasta las "Cortes"- con la idea básica e histórica del Poema, o sea el antagonismo entre los "ricos homes" y el "infanzón", la lucha al fin victoriosa del Cid contra los nobles. (Véase la nota anterior). Esa "unidad" del Poema, como síntesis de crónica y "novela", es una consideración que en sí misma queda al margen del presente estudio, pero que no debemos perder de vista. 
que llevan como regalo del Cid no les servirán para nada, pues éste se convertirá inmediatamente de protector en enemigo (v. 2894). Más aún: ni siquiera después de haber cometido un crimen tan brutal como estúpido -y es la estupidez el punto que aquí importaactúan como se esperaría de gente de su tipo: no convienen en callar lo hecho ni tampoco apresuran su viaje a Carrión, donde estarán protegidos en el círculo de sus familiares. Por el contrario, "alabándos' ivan ifantes de Carrión" (v. 2763), pregonan en voz alta lo que debieran ocultar, no siendo, según sus actitudes precedentes y según lo que sobre ellos nos indica el juglar, hombres de índole quijotesca, sino - a pesar de su condado- los más burgueses que se pueda imaginar, y que volverán a serlo cuando ya resulte tarde.

Tal es, en líneas generales, la impresión que de la "Afrenta de Corpes" debe tener un lector a la vez sincero y despreocupado. Nuestro episodio sería, así, ejemplo prístino de un género literario poco apreciable, pero cultivado hasta nuestros días: el de la novela criminal en que las acciones obedecen a impulsos anormales sin motivo, características que, en el Cid, desentonarían por completo con el resto del poema. Pero esta impresión ingenua no puede ser la acertada, como nos lo demuestra ya un detalle a que antes hemos aludido: el maltrato infligido a doña Elvira y doña Sol no es efecto súbito de un ataque de sadismo, algo como un "contragolpe" psíquico después de una noche de lujuria, según podrían hacerlo suponer algunas indicaciones (vs. 2703, 2720 s., 2735 ss.). No: el maltrato es absolutamente premeditado (2547 s., 2551 ), es elemento integrante de un plan para huir de la corte del Cid. Debemos preguntarnos, pues, qué impulsó a los Infantes a adoptar esa actitud tan calculada.

No recuerdo haber encontrado, en la bibliografía ya bastante extensa sobre el Cid como obra de arte, una sola interpretación que salve la "unidad poética" del episodio en sí mismo y en cuanto parte del Poema. No viene al caso, por ejemplo, hablar ampulosamente del Grollen ("encono") de los Infantes ${ }^{6}$, ya que esta palabra se refiere a una reacción "leonina" y heroica más que a la descrita en el episodio. Motivo mucho más sustancial sería el "egoísmo", reconocido por Huerta como impulso básico de toda la actitud de los Infantes. Pero tampoco así llegamos al meollo, ya que el egoísmo, por definición, impulsa a cuidar de los propios intereses vitales, mientras que, por el contrario, lo que en este episodio hacen los Infantes es olvidar pasajeramente todo lo que importa a su existencia, en cuanto exterior y "burguesa". El simple egoísmo no nos ayuda a comprenderlos. Habrá que pensar en un egoísmo patológicamente exagerado, que convierte al hombre en enemigo de sí mismo y destructor de sus propias construcciones. Un egoísmo "introvertido" por causa de un

${ }^{\circ}$ E. R. Curtius en $Z R P h, 5^{8}$ (1938), p. 171 . 
"complejo de inferioridad", como hoy se dice: tal es, a mi parecer, el estado anímico de los Infantes, el que motiva y unifica sus actitudes, tan sensiblemente antagónicas a su actitud moral; es eso lo que los mueve a cometer la sevicia del Robledo, y lo que tan amargos remordimientos les causará cuando recobren el sentido común.

¿Cuál pudo ser la experiencia vivida por los Infantes - desde que entran en la escena del Poema-, que tan funestas consecuencias tendrá para su vida, planeada hasta entonces con tanto cuidado y tanta frialdad? Es, sin duda, la experiencia del "león" (serie 112). Mucho más vergonzosa, a decir verdad, ha sido su conducta en la batalla contra Búcar, en la cual entran a causa de su susceptibilidad ante las palabras bien intencionadas del Cid (ser. 116 s.). También en esta ocasión hubiera podido fijarse en ellos un "complejo", dada su peculiar mentalidad retorcida que, "proyectando" infaliblemente sobre otras personas sus propios defectos, les hace sospechar, en cada palabra que se les dirige, un veneno oculto. Cuando el Cid, "magníficamente ciego ante ciertas pequeñeces" (Hucrta, op. cit., p. 176), y engañado además sin malicia por Minaya, los recibe tras la batalla con felicitaciones sinceras aunque no merecidas, el poeta añade con perspicacia psicológica: "Por bien lo dixo el Cid, mas ellos lo touieron a escarnio" (v. 2464$)^{\top}$. Sin embargo, Ferrando se ve libre de la vergüenza pública, en el caso de la batalla, gracias al simpático gesto de Pero Vermúdez (ser. 115), y así el combate no es para ellos el recuerdo más humillante, por más que, también en este caso, "vassallos de mio Giid sediense sonrrisando", “... e las noches e los días tan mal los escarmentando" (vs. 2532, 2536). En cambio, la aventura del león los ha expuesto al ludibrio público; por lo tanto, es ella la que ha quedado, en su espíritu susceptible por frío y cerrado, como recuerdo de "plancha" irremediable. Lo que a ambos les hiere, privados como están de todo sentido caballeresco, no es la consciencia de la vergüenza misma, sino sólo el recuerdo de la "publicidad" que ha tenido. De ahí que, en el curso de la "Afrenta", ninguno de ellos llegue a referirse a la batalla: lo único que mencionan es "la del león", y no una, sino cuatro veces, antes y después de la ejecución del crimen: "ante que nos retrayan lo que cuntió del león" (v. 2548),

7 Debo hacer constar aquí una discrepancia mía con la interpretación de Huerta, op. cit., pp. 183-184. Para él, las palabras del Cid, dirigidas a sus yernos antes de la batalla contra Búcar, intentan excusarlos, sinceramente, de participar en ella, y los Infantes, para no "quedar por debajo del héroe", y casi desobedeciendo a su "consejo", le piden "la delantera" (vs. 2931 ss., ser. 115). Para mí, en cambio, las palabras del Cid, dichas con ironía bondadosa y muy velada, tienen carácter pedagógico: el Campeador parece dispensarlos de la pelea, pero en realidad los provoca a entrar en ella, y de ese modo acaba por conseguir lo que secretamente había intentado. Este modo de interpretar el pasaje en cuestión nos permite relacionarlo con la alabanza posterior $(2462 \mathrm{~s}$.$) , la cual asimis-$ mo es de índole pedagógica, aunque no de índole irónica. 
"antes que nos retrayan lo que fo del león" (2556), "nós vengaremos aquésta por la del león" (2719), "la desondra del león assí s’irá vengando" (2762): como una obsesión, entra el león en la serie de las "palabras-guías" que, según veremos, ponen su sello expresivo en esta escena. Toda la culpa en "la desondra del león" ha sido de los Infantes mismos. Hubieran podido reunirse con los demás caballeros -que tampoco acometen al león-- alrededor del escaño del Cid, el cual, como Jesús en la barca durante la tempestad, sigue durmiendo (ser, 112). Pero no lo hicieron así. Ellos han sido sus propios ofensores, y nadie más. Sin embargo, guardan para sí tan sólo la ofensa y rechazan toda culpa, haciéndola recaer sobre los que luego se reirán de ellos (vs. $23^{0} 7$ ss.). Ya en aquel momento, el poeta, anticipando lo que tendrá que narrar más tarde, concluye la serie diciendo: "Fiera cosa les pesa desto que les cuntió" (v. 2310).

$¿$ Por qué, pues, ya que quieren vengarse, no se vengan de sus supuestos "ofensores"? Porque son unos cobardes, que no osan retar a hombres fuertes y curtidos en la guerra. El débil, para sentirse fuerte -y así quisieran sentirse los Infantes-, busca a uno más débil. Ejercerán, pues, su venganza en las únicas víctimas que no podrán oponerles resistencia, o sea en dos flacas mujeres. Por supuesto, para poder gozar de tal venganza con absoluta seguridad, lo primero que deben hacer es alejarse de la corte. Así, bajo la presión de una idea fija, un "complejo de inferioridad" que les exige imperiosamente la propia disolución, por absurda que sea, es como nace el plan detallado en los vs. 2540 ss. Es un plan premeditado, sí, pero premeditado bajo el impacto de un estado psíquico anormal.

Quisiera insistir en lo absurdo del estado psíquico, del que sólo algo absurdo podía brotar. El egoísmo normal de los Infantes no bastaría para hacerles tomar tal decisión, antes bien se opondría a ella; era preciso un egoísmo enfermizo, consecuencia de una humillación que los humillados transformaron en ofensa. Sólo así podían perder el contacto con el ambiente en que tanto trabajo habían empeñado para arraigarse, o sea la corte del Cid. Ya no ven otra cosa, ni piensan sino en vengarse de una "ofensa" que no existe, y ven-

${ }^{s}$ Una vez más, me parece insatisfactoria una interpretación por lo visto generalmente aceptada: la que supone que los caballeros, al acudir en torno al Cid, tratan de protegerlo. Lo que yo creo es que ellos -que "en grant miedo se vieron" (v. 2283) - acuden al Cid para protegerse a sí mismos, sintiéndose más seguros en la proximidad de quien es superior a todos, hasta cuando duerme. Cuando el Cid despierta, dirán: "rebata nos dio el león" (v. 2295), palabras de quienes buscan protección, no de quienes la ofrecen. Me parece evidente la analogía con el maravilloso episodio evangélico (Lucas, 8:22 ss.) aludido en el texto. Es verdad que Pero Vermúdez más tarde, al recordar la escena, dirá: "Nós çercamos el escaño por curiar nuestro señor" (v. 3335), pero no olvidemos que él está hablando pro domo, y que busca la "mayor gloria" de sí mismo y de sus compañeros. 
garse con quienes menos pretexto les han dado para sentirse ofendidos. Doña Elvira y doña Sol no se han burlado de ellos, como "se burló" Beatriz del joven Dante (Vita nuova, XIV, 7), y sin embargo, en ellas vengan las burlas de otros.

Así me parece que cobra sentido pleno un detalle del Poema que, en mi opinión, tampoco puede entenderse bien sin una explicación psicológica. Llama la atención el hecho de que el moro Abengalbón, anfitrión generoso de los Infantes durante su paso por Molina, y fiel amigo del Cid, no obstante que se enfrenta a ellos y los maldice al descubrir el perverso plan de sus dos huéspedes de matarlo a traición, y no obstante que prevé la suerte deplorable de doña Elvira y doña Sol (ser. 126-128), no saque a las hijas del Cid de entre las garras de sus abyectos maridos, sino que pasa todo por alto con una disculpa que más bien es un pretexto: "Si no lo dexás' por mio Çid el de Bivar..., luego levaría sus fijas al Campeador leal" (vs. 2677 ss.). De nuevo es imposible contentarse con una explicación estrictamente formal: de haber salvado el moro a las dos mujeres, la "novela" se habría acabado; no habría habido ni "Afrenta" ni "Cortes". Es así, sin duda; pero cabe preguntar: ¿por qué un poeta tan seguro de sí mismo ha esbozado un episodio - la cuestión entre los Infantes y Abengalbón- que luego no podría desarrollar? Creo que el juglar se ha propuesto subrayar de nuevo el carácter ruin de los dos antihéroes, oponiéndolos una vez más a un hombre de situación modesta comparada con la suya, pero superior a ellos física y moralmente ("mucho era buen barragán", v. 2671) . Al decir el moro a los Infantes, franca y brutalmente, lo que piensa de ellos - cosa que "a los ifantes non plaze" (v. 2676 ) -, pone el último rasgo en la caracterización que el poeta ya había completado antes, y prepara al lector para la escena que habrá de desarrollarse en el robledo.

El maltrato de las hijas del Cid, que a primera vista podría impresionarnos como una explosión de sadismo sexual (véase supra, p. 295), se revela así como algo más digno del poeta, tan reservado, sobrio y casto; y, me atrevo a decir, como algo simbólico. Los infantes, al azotar a sus mujeres, se brindan la ilusión del regodeo que habrían experimentado al vengarse en los caballeros del Cid, cosa

- Huerta, op. cit., pp. 180-181, señala cómo los Infantes, modelos de bajeza, están separados por una enorme distancia moral no sólo del Cid, dechado de sublimidad, sino también de sus vasallos (un Muño Gústioz, por ejemplo). Según el mismo autor, el sarcasmo con que hablan Muño y otros denota envidia y odio (vs. 2326 ss.), mientras que el humorismo del Cid -y también de un personaje como el Conde Berenguer- presupone una desenvoltura espiritual, por encima de las pasiones. Sin embargo, también el Cid puede hablar con sarcasmo ("ondra", v. 2891): ne quid nimis! Y no está exento de fallas humanas: ha preferido ser buen vasallo a ser buen padre, y no ha resistido a la seducción que suponía el honor de emparentar con una familia más noble que la suya (vs. 2084 ss.); más tarde lo confesará él mismo a las dos pobres 
que ni siquiera han osado intentar. Cada golpe de espuelas y de "çinchas corredizas" (v. 2736) que cae sobre esos cuerpos indefensos reemplaza, para ellos, otros tantos golpes de espada o de lanza que quisieran haberse atrevido a dar a sus supuestos "ofensores", los hombres de la mesnada del Cid. En la repulsiva escena se purgan, pues, del "complejo de inferioridad" bajo cuyo dominio exclusivo la han preparado. Sin pensar en las malas consecuencias que su actitud habrá de acarrearles, golpean y golpean, impulsados sólo por el deseo subconsciente de recobrar el sentimiento de su superioridad, perdida y arruinada en la humillación de "la del león". Sería erróneo pensar que, al maltratar a doña Elvira y doña Sol, tuvieran la intención de ofender in absentia al padre, al Cid. Tal intención supondría cierto ánimo valeroso, pero ellos no son sino cobardes. Más bien podemos decir que, de haberles venido esa idea, se habrían sentido cohibidos por el miedo y no habrían seguido golpeando. Actúan sin ninguna "intención" racional; el maltrato se hace por sí mismo, sólo como manifestación de un estado patológico que quiere curarse.

Comparemos sus otras actitudes, vecinas a ésta. El plan de asesinar al moro hospitalario nada tiene que ver con el "complejo": brota de su codicia, de su estado normal de no-caballeros; lo habrían concebido aun sin la humillación que les corroe el alma. Del mismo modo, vueltos ya a su sentido común, planearán más tarde la matanza insidiosa de los caballeros del Cid en Carrión (vs. $353^{8}$ ss.), impulsados esta vez no por la codicia, sino por el miedo de enfrentarse con sus adversarios en un duelo público. Es un plan digno de la índole normal de los dos, y tampoco presupone en ellos ningún estado psíquicamente extremo, dada su manera de ser, presentada ya por el poeta con todos los posibles rasgos desfavorables, a fin de contrastar la perfecta ruindad con la perfecta nobleza de ánimo, personificada en el Cid. Y para hacer resaltar más claramente aún el contraste entre el crimen irracional del robledo y las actitudes "racionales" o normales de los Infantes, fijémonos en un hecho revelador: el asesinato del moro y de los tres caballeros se planea pero no se ejecuta. ¿Y por qué no? Porque velaban en ellos, impidiéndoles la consumación del plan, sus guías normales en la vida: el sen-

víctimas de su ambición: "Yo tomé el cassamiento, mas non osé dezir ál" (v. 2891). No se puede insistir lo bastante en el hecho de que el encanto de la personalidad del Cid en el Poema consiste precisamente en que es hombre natural (véase supra, nota 3), humanamente imperfecto, aunque -eso sí- superior en todos los sentidos a su ambiente. Ni es "mítico", ni "sobrenatural", ni "santo", $m$ " "héroe nacional" - si queremos escuchar lo que el juglar nos sugiere en cada página de su Poema. Sobre la envidia, defecto ingénito casteIlano, véase también Ment́ndez Pidal, el Cid Campeador, pp. 311-312. En más de un sentido, el Cid del Poema tiene parentesco espiritual y moral con el Goffredo del Tasso, tema que he tratado en mi libro Ritterepos-Gottesepos. Torquato Tassos Weg als Dichter, Köln, 1958, cap. 10. 
tido común, la prudencia, la cobardía. "El cometer fue malo, que lo ál no s'enpeçó, / ca grand miedo ovieron a Alfonsso el de León", dice el poeta (vs. 3542 s.), con una de esas formulaciones suyas tan escuetas como contundentes, refiriéndose al segundo de los dos planes. En cambio, la "afrenta" no sólo se planea, sino que se ejecuta, porque en esa oportunidad única nada vela en ellos sino el "complejo" que acaba con todo cuanto en ellos es "racional".

Y he aquí el último paso de este desarrollo psíquico, y el menos comprensible si no pensamos que actúan bajo el efecto de una especie de pesadilla: los Infantes no tratan de ocultar su fechoría, sino que la pregonan y "se alaban" de ella. Para que dos hombres de ordinario tan cautelosos lleguen a publicar una brutalidad tan peligrosa para ellos mismos, deben de haber estado fuera de su estado normal, y podemos decir que en este sentido se superan a sí mismos por un momento. Ellos que, en general sólo planean y no realizan los actos de cobardía, ahora no sólo ejecutan el más cobarde de todos, sino que lo pregonan. El poeta, descubridor de almas, sabe lo que hace cuando nos dice tres veces seguidas: "por los montes do ivan, ellos ívanse alabando" (v. 2757); "alabándos' ivan ifantes de Carrión" (2763); "alabándos' sedían ifantes de Carrión; / por todas essas tierras estas nuevas sabidas son" (2823 s.). ¿A qué impulso obedecen, pues, al comportarse a tal grado contra sus propios intereses prácticos? La respuesta me parece evidente. Para acabar de liberarse de la "humillación" que tanto les escuece, no les basta con haberse "vengado": deben todavía hacer del dominio público una venganza que, para ellos, ha tenido el carácter "simbólico" de una lucha victoriosa contra sus ofensores en la corte del Cid.

Lo que trato de presentar como impulso secreto de los dos actores principales en la escena monstruosa del robledo, el poeta mismo nos ayuda a comprenderlo mediante un recurso conocido con el nombre de Leitworte, o sea con el empleo de ciertas "palabras-guías" que, reapareciendo a menudo y enfáticamente, denuncian en el autor o en sus personajes un estado anímico que de esa manera se expresa, aun a pesar suyo. Así nos encontramos, en boca de los Infantes, con varias palabras que usan reiteradamente en este solo episodio, mientras en las escenas posteriores el uso de esas palabras cambia de manera interesante. Ya hemos hablado de la repetida alusión al león. manifestación irresistible, en sus propios labios, del impulso principal -no por vergonzoso, sino por público- que los ha inducido a su perverso plan. Además, expresan tres veces, durante la "Afrenta", la idea de venganza, el sentimiento que ha inundado todos sus pensamientos y que, en el fondo anímico, desconocido por ellos mismos, es una venganza dirigida contra su propia naturaleza miserable: "nós vengaremos aquésta por la del león" (v. 2719), "de nuestros casamientos agora somos vengados" (2758), "la desondra del león assí 
s'irá vengando" (2762). Otra palabra-clave, que delimita el tipo de la "venganza", es escarnir, empleada también tres veces en el episodio: "escarniremos las fijas del Canpeador" (2551), "assí las escarniremos..." (2555), "aquí seredes escarnidas en estos fieros montes" $(2715)$. (No olvidemos que ellos mismos, v. 2464, ya "touieron a escarnio" unas palabras bien intencionadas que se les habían dirigido; de modo que estamos ante una "venganza" moldeada exactamente sobre la "ofensa", cuando ellos, por su parte, "escarnecen" a sus mujeres). Y añadamos el alabarse ya comentado, palabra que repiten no los Infantes, sino el poeta, para designar la manifestación definitiva del "complejo de inferioridad".

Cuatro palabras-guías, todas brotadas del sentimiento de ofensa, deseo de venganza, especificación de la venganza y gozo después de haberla realizado; y ninguna que pueda sugerir que haya, en la "Afrenta", algo como una satisfacción sádica y sexual. El fenómeno estilístico que hemos observado nos ayuda, pues, a desechar la primera impresión del lector superficial, y a sustituirla por la que, desde todos los puntos de vista, hemos sentido sugerida ya por el poeta.

Él los deja ir "alabándose" y, por el momento, no se ocupa más de ellos: "Mas yo vos diré d'aquel Félez Muñoz" (v. 2764). Debemos imaginarnos, sin su dirección, cómo los Infantes, al volver a sus tierras, vuelven también a su estado normal de egoísmo prudente y cobarde, encontrándose sin duda como quien despierta después de una noche de borrachera. Atrás ha quedado la locura que, de manera excepcional, turbó su sentido común acostumbrado. No nos los muestra el poeta en el momento en que han debido darse cuenta, con susto, de la difícil situación a que su desvarío los ha llevado. Pero nos ayuda a adivinarlo con otras señales, por medio de las "palabras-guías" ya no presentes, sino ausentes ${ }^{\mathbf{1 0}}$.

Fijémonos en esa "ausencia" expresiva. Al defenderse de las recriminaciones del Cid ante las Cortes, Ferrando y Diego no alegan sino su "natura de condes de Carrión" (series 141, 145) y la consiguiente imposibilidad de un matrimonio con mujeres de más bajo nacimiento, según sus prejuicios. No mencionan las humillaciones infligidas a su cobardía en la corte del Cid; hacen como si no hu-

10 La "ausencia expresiva" de ciertas palabras - lo que podríamos llamar negative Leitworte- hace recordar los "silencios" - palabras "ausentes"- de cierta lírica moderna, tratados por Amado Alonso. Véase el artículo notable aunque algo unilateral de Claudio Guillén, "Estilística del silencio", RHM, 33 (1957), especialmente pp. 263-264, y otros trabajos de la nueva escuela estilística española. Séame permitido, sin embargo, referime a lo que yo mismo, hace treinta años, traté de explicar sobre el carácter estilístico de las "conversaciones silenciosas" ("Schweigegespräche") (Fogazzaros Stil und der symbolistische Lebensroman, Heidelberg, 1928, en especial pp. 97 ss.). Por lo visto, los pregoneros del movimiento dinámico español tienen un poco el prejuicio de que, antes de ellos, no hubo nada de estilística. 
biera acontecido nada de lo que - como hemos visto- les ha impulsado a consumar la afrenta. Si las cosas siguieran según lo desearían ellos, "la del león" con todo el resto quedaría sepultado ya en el olvido. Y esto, considerado en su aspecto psicológico, quiere decir que la "costra" o "coraza" que envuelve sus almas, rota por poco tiempo en virtud de su "complejo", ya se ha restaurado. Son ahora lo que antes habían sido: dos jóvenes aristócratas presumidos que quisieran persuadirse a sí mismos y hacer creer a sus adversarios que "más nos preçiamos, sabet, que menos no" (v. 3300), y que "por que las dexamos, ondrados somos venidos" (v. 3360). Tampoco repiten lo del "escarnio" ni hablan de "venganza"; no mencionan ningún detalle de la afrenta, pues ahora - a pesar de su fachada orgullosa y satisfecha- quisieran no haberla cometido nunca. Lo que se oculta tras la fachada, nos lo hace ver el poeta cuando dice que al Cid "nol pueden catar de vergüença ifantes de Carrión" (v. 3126).

No sólo han desaparecido de boca de los Infantes las "palabrasguías" de la "Afrenta"; tampoco el poeta dice ya que "se alaban". Lo que ahora dice y repite nos confirma en la impresión de que, durante aquel episodio, ellos se encontraban mentalmente fuera de sí mismos y que ahora, demasiado tarde, han vuelto en sí11: "Ya les va pesando..." (v. 2985), "aquí veriedes quexarse ifantes de Carrión" (3207), "mucho eran repentidos los ifantes..." (3557), "ya se van repintiendo ifantes de Carrión; / de lo que avién fecho, mucho repisos son; / no lo querrién aver fecho por quanto ha en Carrión" (3568 ss.). En lugar de "alabarse", tenemos ahora repentirse, quexarse. Huelga decir que no es éste un arrepentimiento que indique algo como un cambio moral en ellos. Lo que pasa es sólo que, después de haber procedido como cobardes y egoístas sin sentido común, ya han vuelto a ser egoístas y cobardes con sentido común, y que, por lo tanto, nada anhelarían tanto como poder renegar de sí mismos, borrar su conducta insensata. El juglar del siglo xn ha logrado hacer visible y persuasivo en sus dos antihéroes, desde las "Bodas" hasta las "Cortes", un estupendo desarrollo psíquico, de cuerdos a locos, y luego de locos a cuerdos; desarrollo que, en cuanto concepción artística, no es inferior a otro del mismo tipo, imaginado y elaborado cuatrocientos años más tarde: la locura y la cordura de Orlando, vistas por Ariosto (Orlando furioso, XXIII, XXXIX).

Algo de consternación y no sólo de furia y tristeza ante lo acontecido en el robledo se hace sentir también en las preguntas que el Cid, al iniciarse la querella, dirige a quienes fueron sus yernos.

${ }^{11}$ El "arrepentimiento" de los Infantes, dice HuerTa, op. cit., pp. 209-210, encaja en la "mitificación de las espadas del Cid"; y añade que las expresiones del juglar, al referirse al arrepentimiento, están variando: prueba de la vitalidad con que se le ha presentado este rasgo. 
En lugar de echarles simplemente en cara su crimen, les pregunta -y repetidas veces, con énfasis anafórico- "por qué" lo han hecho: "¿A quém descubriestes las telas del coraçón?... ¿̇Por qué las sacávades de Valencia...? ¿̇A qué las firiestes a çinchas e a espolones?" (3260 ss.). El Cid pregunta como lo hace un hombre dueño de sí mismo, incapaz de comprender lo que han hecho unos mentecatos.

¿Y aquellas "palabras-guías" que habían acompañado a los dos malvados durante la "Afrenta", simbolizando su estado mental, y que no pronuncian ya después que han vuelto a "encontrarse a sí mismos"? Lo que ocurre ahora es que quienes usan esas palabras son sus adversarios. Los Infantes ya no mencionan "la del león": es Pero Vermúdez el que ahora les hace recordar toda la historia ridicula y humillante (3330 ss.), y Martín Antolínez la repite una vez más $\left(33^{6} 3\right.$ ss.). Ya ellos no hablan de haberse "vengado": ahora, la "venganza" corresponde al padre ofendido, al Cid: "De mios yernos de Carrión Dios me faga vengar" (v.2894), “assí s'irán vengando don' Elvira e doña Sol" (3187), "grado al rey del çielo, mis fijas vengadas son" (3714). Y en cuanto al "escarnio", es el poeta mismo, el adversario más encarnizado de los Infantes, quien les tomará esta palabra de los labios, y dirá en el lugar prominente donde formula la "moraleja" de su historia: "Qui buena dueña escarneçe e la dexa despuós, / atal le contesca o siquier peor" (3706 s.). Notemos, de paso, que con estas últimas palabras la "Afrenta" cobra carácter de "ejemplo" para "ilustrar" el "caso" de la mujer maltratada por descortesía, y del castigo que corresponde a los culpables, - una prueba más de que nuestro episodio es "novela" y no "crónica".

Este punto -que, por lo demás, no pertenece directamente al tema aquí estudiado - tiene su confirmación en otro hecho: hay también, en el Poema, unas bodas históricas; y ocurre que éstas se cuentan de manera muy distinta de como se narran las "bodas" inventadas. Sabemos cómo, para enaltecer más el bien merecido triunfo del Cid, en medio de la tercera "demanda" puesta por los del Gid a los Infantes, con motivo de la "rencura mayor" (v. 3254), el poeta hace llegar a las Cortes, como caídos del cielo, a dos embajadores de reyes que le piden al Cid la mano de sus atribuladas hijas (3392 ss.). El episodio tiene carácter de ingenuo happy end. El lector no preparado diría probablemente que son éstas las bodas inventadas, y las de los Infantes las históricas ${ }^{12}$. $\mathrm{Ni}$ se presentan los dos pretendientes nuevos, ni hay la menor complicación; en pocos versos (3392-3428) ya se ha acabado el episodio. Los "dos cavalleros" no llegan a hablar por sí mismos: el poeta resume en pocas frases sus palabras; dice además que le "besan las manos" al rey y nos hace saber sus nombres,

\footnotetext{
12. Véase, sin embargo, mi nota 4, donde llamo la atención sobre la relación interna de las "segundas bodas" con la idea central del Poema. Es sabido que el poeta trata también con libertad las "bodas históricas".
} 
que Menéndez Pidal ha logrado identificar en los documentos ${ }^{13}$. Porque lo que sucede es que - a pesar de las apariencias antes señaladas- - estas segundas bodas les llevan a las primeras la única ventaja de que tienen "realidad histórica" y no "realidad poética" ${ }^{11}$. En lo demás son mucho menos interesantes; sólo son un pretexto estructural que sirve al poeta para rodear de un último resplandor a sus amigos del Poema - los únicos a quienes deja la palabra en este episodio- y para poner el sello definitivo en la ignominia de sus enemigos: “. . mas non plaze a ifantes de Carrión" (v. 3428).

Había dos razones para que el juglar tratara tan superficialmente, casi como simple adorno, estas segundas bodas que en la realidad histórica fueron, con toda probabilidad, las únicas. Primero, no quería repetirse: de "bodas" había habido bastante en su Poema. Segundo, aun de haber querido introducir detalles, no podía esta vez sino reproducir con cuidado lo realmente acontecido, puesto que las bodas históricas eran de fecha reciente y la mayoría de los participantes seguían viviendo cuando él escribía. La fuerza de la invención, la perspicacia de su mirada psicológica, su fantasía y expresividad habian tenido libre juego en las bodas inventadas, en la "novela", en la realidad poética; en las bodas históricas habría tenido que refrenar, en favor de la realidad acontecida, esas dotes poéticas —sus dotes más características--, hasta sofocarlas o poco menos.

Así, pues, en este caso como en otros, un gran poeta ha tenido el poder de imponer su visión en lugar de lo históricamente real. Los "Infantes" - así delineados, conforme a las intenciones del ju. glar- podían resultarle tan persuasivos y vivos solamente porque eran fruto de libre invención, en cuanto a su carácter. $Y$ por consiguiente, las hijas del Cid llevan para la posteridad el sello de "mal casadas", a pesar de que en la realidad no lo eran, y de que el mismo poeta, a fuer de cronista fiel, menciona esa realidad al final de su Poema. De modo que, a pesar de todo, han predicho la verdad los miserables Infantes cuando uno de ellos proclamaba: "Lo que les fiziemos seer les ha retraydo" (v. 3359). Pero no es Diego Gonzálvez, es el poeta mismo el responsable de esto.

ULRICH LEO

University of Toronto.

¿a Gran edición del Poema, t. 2, s. vv. "Oiarra" y "Yénego Siménez" (con adiciones en la $4^{3}$ ed., pp. 1217 s.). A propósito de los nombres, es verdad que Menéndez Pidal ha logrado probar también la historicidad de los dos Infantes (véase supra; nota 4). Tan sólo menciono aquí una complicación que -para el Poema- surge de los dos matrimonios de las hijas del Cid, el ficticio y el real: ¿cómo pueden ellas - en el Poema-casarse con los dos nuevos pretendientes, estando ya casadas - je indisolublemente! - con los Infantes?

${ }^{14}$ Sobre esto, cf. el último ensayo de mi libro Sehen und Wirklichkeit bei Dante, Frankfurt, 1957 ("El problema de la historia de la literatura"). 